\title{
Sensibilidades educativas no processo de avaliação de aprendizagem no fórum de discussão da EaD
}

Fabiana Araújo Sousa fabianaifpi@gmail.com 0000-0002-0746-8007 Instituto Federal de Educação, Ciência e Tecnologia do Piauí, Teresina, Piauí, Brasil.

Iranilson Buriti de Oliveira iburiti@yahoo.com.br 0000-0001-8176-6670 Universidade Federal de Campina Grande, Campina Grande, Paraíba, Brasil.

\begin{abstract}
RESUMO
Os avanços das Tecnologias de Informação e Comunicação - TIC estão possibilitando o crescimento e melhoria da modalidade de ensino a distância. Todavia, é essencial realizar reflexões e discussões acerca de alguns instrumentos pedagógicos utilizados na Educação a Distância - EaD. Assim, este artigo tem como objetivo demonstrar o resultado de uma pesquisa, que teve os objetivos: identificar as mediações pedagógicas e analisar as sensibilidades dos professores-tutores do curso técnico Serviços Jurídicos, do Instituto Federal de Educação, Ciência e Tecnologia do Piauí, durante a prática avaliativa no fórum do Ambiente Virtual de Aprendizagem - Moodle. Metodologicamente, utilizamos as abordagens qualitativa, e como instrumentos de coleta de dados a observação não participativa na plataforma de aprendizagem e entrevista semiestruturada com os professores-tutores. Resultados indicam marcas de sensibilidades nas práticas avaliativas dos professores-tutores, pois durante o ato de avaliar os fóruns tiveram empatia a situações particulares dos alunos, respeitando sua subjetividade, valorizando suas opiniões, bem como utilizando o bom senso nesse processo avaliativo.
\end{abstract}

PALAVRAS-CHAVE: Educação a distância. Papel do professor-tutor. Avaliação de aprendizagem. Mediações pedagógicas. Sensibilidades educativas. 


\section{INTRODUÇÃO}

A Educação a Distância - EaD vem ganhando mais espaço nas instituições de ensino devido o rápido avanço e visibilidade das Tecnologias da Informação e Comunicação - TIC no processo educativo, possibilitando por meio dos Ambientes Virtuais de Aprendizagem - AVA, com suas ferramentas interativas como o chat e o fórum, nos quais os participantes podem fazer perguntas, trocar ideias e construir uma rede de conhecimentos.

No contexto atual que intensifica e transforma as tecnologias em instrumentos pedagógicos, a EaD que é uma modalidade de educação a qual os discentes e docentes encontram-se em lugares diferentes (MOORE; KEARSKEY, 2011; CARLINI; TARCIA, 2010), pode ser considerada uma oportunidade para que as pessoas, que de alguma forma foram excluídas dos processos educacionais tradicionais, voltem a estudar. No entanto, essa modalidade de ensino ainda é um desafio para os professores e alunos, pois o processo de ensino e aprendizagem requer, destes, autonomia e disciplina, e daqueles uma preparação para conduzirem o trabalho em grupo, desenvolver um cotidiano criativo na interface digital, saber guiar diversas situações simultâneas e dominar o conteúdo envolvido nos projetos.

Outro contexto interessante converge para a Educação online "um evento da cibercultura e não apenas uma geração e evolução das clássicas práticas curriculares da Educação a Distância" (SANTOS, 2005, p. 31). Portanto, em decorrências das TIC a EaD online tornou-se um modelo que utiliza as práticas pedagógicas de forma mais interativa, através da cooperação e colaboração praticadas nas comunicações por meio das ferramentas interativas, que são pressupostos da cibercultura.

Segundo Lévy (1999, p. 15), "a cibercultura expressa o surgimento de um novo universo, diferente das formas que vieram antes dele no sentido de que ele se constrói sobre a indeterminação de um sentido global qualquer". Estas mudanças foram provocadas pelos avanços tecnológicos das telecomunicações, especialmente, da internet.

Em consequência desse advento, que possibilitou uma maior interatividade, as salas de aula obtiveram novas características, como por exemplo: mediações online de atividades e criação de grupos de estudo através das ferramentas interativas. Desta forma, os Ambientes Virtuais de Aprendizagem - AVA, que são plataformas onde há vários recursos de comunicação e de informática, admitem ocorrer práticas pedagógicas entre professores e alunos.

Há várias nomenclaturas utilizadas para designar os AVA, como sala de aula virtual, ambiente de ensino a distância, ambiente digital de aprendizagem, VLE (virtual learning environment), entre outros. No entanto, este estudo utilizou a sigla AVA e o conceito de Faria e Lopes (2014, p. 49): "Ambiente virtuais de aprendizagem são softwares desenvolvidos sobre uma metodologia pedagógica para auxiliar a promoção de ensino e aprendizagem a distância ou semipresencial".

O AVA mais utilizado por instituições de ensino, por ser gratuito e de fácil manuseio é o MOODLE "software livre que atua como ferramenta de processo dinâmico de aprendizagem por meio de trocas, orientado por uma filosofia de 'pedagogia social construtivista'"' (DUBEUX et al, 2008, p. 5). Esta plataforma tem as seguintes características: a permissão de acesso restrito a usuários cadastrados; 
há espaços para inserir o material das aulas dos professores e atividades dos alunos e possuem várias ferramentas de comunicação, como o fórum.

Assim sendo, a $\mathrm{EaD}$ via internet ou online vem alcançando vários simpatizantes, porque é realizada via redes e ainda tem como pressuposto uma aprendizagem colaborativa (MORAN, 2007). No entanto, acreditamos que ainda falta ser discutida com profundidade nessa modalidade de ensino as sensibilidades educativas no processo avaliativo.

O assunto na sua complexidade nos assinala que "a conduta do avaliador interfere e influencia a conduta do sujeito avaliado de maneira recíproca" (BRUNO; MORAES, 2006, p. 53) - e também controvertido, podendo ser vista de duas maneiras opostas: como uma simples forma "medir a retenção de informações e a capacidade de repetir o que foi dito" (PRIMO, 2006, p. 38) ou com o objetivo de "acompanhar o processo de construção ativa do conhecimento e incentivar a capacidade autoral e inventiva dos aprendizes" (idem).

Nesse contexto, compreendemos que o processo avaliativo é parte integrante do ato educativo. Dele há a possibilidade de perceber o modo de se construi-lo. Deste modo, este estudo justifica-se porque, apesar dos avanços que a Internet proporciona ao ensino a distância, a falta de credibilidade dos métodos de avaliação nessa modalidade de ensino ainda é uma realidade (ALVES; ERRICO; MESQUITA, 2002), e refletir acerca das sensibilidades dos professores-tutores em relação ao processo avaliativo no instrumento de interatividade fórum contribuirá para entendermos novas formas de ver e sentir a avaliação de aprendizagem no fórum do AVA-MOODLE.

Diante desse contexto, este artigo tem como objetivos: identificar as mediações pedagógicas e analisar as sensibilidades dos professores-tutores do curso técnico Serviços Jurídicos, do Instituto Federal de Educação, Ciência e Tecnologia do Piauí, durante a prática avaliativa no fórum do Ambiente Virtual de Aprendizagem - Moodle.

Esse termo sensibilidade, no presente estudo, foi norteado pelo conceito da historiadora Sandra Pesavento (2005, p. 08) que entende como "as formas pelas quais indivíduos e grupos se dão a perceber, comparecendo como um reduto de representação da realidade através das emoções e dos "sentidos". Por conseguinte, utilizamos esse conceito com o sentido de capacidade de ser sensível, sentir emoções, sentimentos, empatia; enfim, tudo que estiver relacionado às sensações e a função que essas têm nas representações de uma cultura, que tanto podem ser manifestadas por meio de discursos como nas práticas sociais.

\section{PRÁTICA DE AVALIAÇÃO NO CONTEXTO DA EAD}

Para entendermos a avaliação de aprendizagem no âmbito da Educação a Distância - EaD precisamos compreender, primeiramente, se esta modalidade de ensino utiliza no processo de ensino e aprendizagem, suportes tecnológicos de informação e comunicação, que vêm contribuindo para mudanças significativas nas estratégias de ensino, aprendizagem e avaliação.

Segundo Barros et al. (2008), 
às formas metodológicas atuais organizadas para a aprendizagem. Quando falamos em educação online estamos nos referindo à educação não presencial mediada por tecnologias digitais. Isso engloba vários elementos como a EaD, os E. B. M. learning(s), entre outros. Pode ser entendida como um conjunto de ações de ensino e aprendizagem que são desenvolvidas através de meios telemáticos como a Internet, a videoconferência e a teleconferência. A educação online nos traz questões pedagógicas específicas com desafios novos para a EaD e a presencial. Para o uso da educação online um dos maiores desafios está na compreensão da diferença do paradigma virtual e do presencial na utilização das interfaces da tecnologia disponíveis para a aula (BARROS, 2007, p. 6).

Com efeito, a modalidade de educação a distância é reconhecida no Brasil através da Lei de Diretrizes e Bases da Educação - LDB, que no seu artigo 80 passa a dar mais reconhecimento a $\mathrm{EaD}$, definindo-a como:

Modalidade educacional na qual a mediação didático-pedagógica nos processos de ensino e aprendizagem ocorre com a utilização de meios e tecnologias da informação e comunicação, com estudantes e professores desenvolvendo atividades educativas em lugares ou tempos diversos. (BRASIL, 1996).

\section{Corroborando Moore e Kearsley (2011) conceituam a EaD como:}

Educação a distância é o aprendizado planejado que ocorre normalmente em um lugar diferente do local do ensino, exigindo técnicas especiais de criação do curso e de instrução, comunicação por meio de várias tecnologias e disposições organizacionais e administrativas especiais (MOORE; KEARSLEY, 2011, p. 2).

Notamos nos conceitos que, para a EaD, a aprendizagem acontece na maioria das vezes com a separação física entre o professor e o aluno, e com a presença da tecnologia, que contribui na efetivação da comunicação e no processo de ensino e aprendizagem.

Percebemos, ao longo dos tempos que a EaD aliada com as Tecnologias da Informação e Comunicação - TIC ocasionaram mudanças ao campo educacional. Entretanto, também adicionou desafios novos, como o processo avaliativo nessa modalidade de ensino.

Assim sendo, a avaliação em AVA de acordo com Bassani e Behar (2009) pode ser compreendida a partir de três perspectivas:
a) avaliação por meio de testes on-line;
b) avaliação da produção individual dos estudantes;
c) análise das interações entre alunos, a partir de mensagens postadas/trocadas por meio das diversas ferramentas de comunicação (BASSANI; BEHAR, 2009, p. 100).

Dessa maneira, para essas autoras a avaliação em AVA poderá ser realizada através de testes online, atividades de produção individual e nas análises das mensagens enviadas por meio das ferramentas interativas de comunicação.

Dessa maneira, considerando a realidade especifica da EaD, o autor Cortelazzo (2013) relata que existem três momentos da avaliação de aprendizagem nessa modalidade: autoavaliação, coavaliação e heteroavaliação. 
Na autoavaliação o aluno autônomo deverá ter a consciência sobre como anda o seu desenvolvimento da aprendizagem. Pode fazer isso, por meio da resolução de questionários, simulados, resumos e elaboração de portfólios. Caso não esteja aprendendo, é necessário verificar o porquê, e buscar solucionar e não, meramente, esperar ser reprovado pela instituição de ensino.

Em relação à heteroavaliação é o momento de avaliação onde se aplica instrumentos como provas objetivas e discursivas para aferir, diagnosticar, mensurar e ponderar a aprendizagem da turma.

Na coavaliação "[...] exige interação entre os sujeitos da aprendizagem, pois é nesse momento que o grupo ter a condição de se avaliar em conjunto, como acontece em fóruns, seminários e mesas redondas". (FARIA; LOPES, 2014, p. 110). Logo, este tipo de avaliação, possibilita os membros de uma determinada equipe, grupo ou turma avaliarem uns aos outros.

O documento Referenciais para a educação superior a distância (BRASIL, 2007, p. 16) afirma: "na educação à distância, o modelo de avaliação da aprendizagem deve ajudar o estudante a desenvolver graus mais complexos de competências cognitivas, habilidades e atitudes, possibilitando-lhe alcançar os objetivos propostos". Deste modo, na EaD a avaliação de aprendizagem precisa contribuir para que o aluno desenvolva uma aprendizagem significativa, não priorizando somente a memorização, mas devendo ressaltar as observações, experiências e descobertas.

De tal modo, devemos pensar a avaliação de aprendizagem como um processo relacional, onde o foco da avaliação afasta-se de somente verificar as construções dos alunos, por instrumento específico, e transfere-se para a relação de construções do conhecimento individual e coletivo e das condições de aprendizagem.

Para Amarilla (2011), aprendemos quando transformamos aprendizagem em conhecimento, o que só pode ser conduzido na relação com o outro, quer a distância ou presencialmente, o que também precisa ser considerado nos processos avaliativos no AVA.

Entendemos que a linha de pensamento do autor é clara quando ressalta por meio da interação com o outro, transformando aprendizagem em conhecimento que, realmente se aprende, seja no ensino presencial ou a distância. Isto deve ser inserido também nas práticas de avaliações no AVA.

Desse modo, a prática da avaliação de aprendizagem processual e contínua pode ser facilitada, uma vez que o AVA armazena as interações, produto dos processos de aprendizagem e construção do conhecimento.

Diante do que foi exposto sobre a avaliação de aprendizagem é necessário relembrarmos a importância do planejamento e o quanto caminha junto com a avaliação, ou seja, dialogam entre si. É simples, embora pareça complexo, na verdade, o educador planeja a avaliação, avalia o planejamento e nesse vai e vem, consequentemente, surgem às práticas que propiciam a construção do conhecimento.

De um modo geral, três pontos devem ser definidos no planejamento de uma avaliação de aprendizagem: a função da avaliação, os critérios de avaliação e as técnicas/instrumentos de avaliação. 
Ressalta Alonso (2005) que quando se fala em avaliação em EaD precisamos pensar em uma proposta educativa, onde o projeto político-pedagógico é que dará sustentação a prática pedagógica vivenciada pelos professores-tutores e alunos que utilizam as Tecnologias da Informação e Comunicação - TIC como mecanismo para desenvolver suas atividades pedagógicas.

Diante desse contexto, vale salientar que na EaD, geralmente não há contatos físicos entre os alunos e o professor que elaborou as atividades avaliativas. Logo, é imprescindível ter uma pessoa para orientar, observar, ajudar e acompanhar o desenvolvimento dos alunos no AVA. Assim, houve a necessidade de criar uma função, um novo profissional para atuar na educação: o tutor.

Todavia, esse método de tutoria não é recente, vem de um processo de aperfeiçoamento, conforme Sá:

[...] a tutoria, como método, teria nascido no século XV. Seu berço teria sido a universidade, onde ela teria sido usada como orientação de caráter religioso aos estudantes, com o objetivo de, nos estudantes, infundir a fé e a conduta moral. Com essa conotação, dão conta os estudiosos, ela teria chegado ao século XIX, onde o tutor terminou por se considerar como o guardião da moral e da fé (SÁ, 1998, p. 45).

A eficácia desse modelo tutorial influenciou a implementação do tutor nas universidades, no século $X X$, com as atribuições de orientar e acompanhar as atividades acadêmicas dos alunos (SÁ, 1998). Atualmente é esta a função adotada pelo tutor nos programas de EaD. Entendemos que é neste processo de acompanhamento do ensino e aprendizagem que o professor-tutor poderá orientar, motivar a participação, indicar possibilidades e caminhos para que o aluno possa ser um sujeito ativo no processo de construção do conhecimento.

Assim, o professor-tutor deverá ser a primeira pessoa a entrar em contato com a turma, na ação estimulante e provocativa da apresentação dos alunos na plataforma de aprendizagem como durante todo o curso, enviando mensagens, motivando a participação nas aulas e mantendo um clima acolhedor, sensível ao perfil dos alunos, gera com isto uma ideia de comunidade, de turma (MATTAR, 2012).

Além das atividades de orientação, acompanhamento da aprendizagem e nas ações relacionadas aos aspectos sociais e afetivos, percebemos que o tutor também exerce atividades como professor ao desenvolver ações pedagógicas e didáticas: incentivar a pesquisa, elaborar atividades, avaliar respostas e estimular e coordenar as discussões.

Nesse contexto, os autores Lázaro e Asensi (apud Silva) definem:

\footnotetext{
ser tutor é ser professor que se encarrega de atender diversos aspectos que não são tratados nas aulas. O tutor também é o professor, o educador integral de um grupo de alunos. A tutoria é uma atividade inerente à função do professor, que se realiza individual e coletivamente com os alunos em sala de aula a fim de facilitar a integração pessoal nos processos de aprendizagem; é a ação de ajuda ou orientação ao aluno que o professor-tutor pode realizar além de sua própria ação docente e paralelamente a ela (LÁZARO; ASENSI, apud SILVA, 2008, p. 37).
}

Portanto, as funções do professor-tutor de aconselhamento, orientação da aprendizagem e avaliação precisam estar interligadas para garantir a efetivação da 
aprendizagem dos alunos (MOULIN et al., 2004). Deste modo, cremos que para conseguir atender essas atribuições, as instituições que oferecem cursos na modalidade a distância inseriram no seu quadro funcional o professor-tutor a distância e o presencial.

\section{AVALIAÇÃO NO FÓRUM DO AVA - MOODLE}

O fórum, recurso analisado por este estudo, é uma das principais ferramentas interativas do MOODLE que "consiste na proposição de uma questão sobre a qual vão sendo feitos comentários, gerando uma 'árvore' de ideia a partir de uma ideia inicial" (VILLARDI; OLIVEIRA, 2005, p. 84). De tal modo, que tanto os professores como os alunos podem fazer comentários, criando-se uma rede de conhecimentos a partir da troca de saberes.

De acordo com Rossato et al. (2013):

Os fóruns, como espaço de aprendizagem, propiciam a comunicação assíncrona, permitem uma aprendizagem marcada pela interação, sem que o tempo seja uma fronteira para sua realização e sem que a ação individual do estudante, que marca os modelos tradicionais de aprendizagem prepondere (ROSSATO, 2013, p. 401)

Nesse sentido, o fórum sendo uma ferramenta de discussão e troca de conhecimentos, possibilita a interação entre os alunos e professores a qualquer momento. Deste modo, compreendemos que contribui para a construção coletiva do conhecimento, possibilitando contribuições bem planejadas, reflexivas, dialogadas e sensíveis, pois ao elaborar um fórum podemos inserir temáticas onde os sujeitos participantes deverão pesquisar para colaborar.

Portanto, o fórum para ser uma importante ferramenta avaliativa é imprescindível que o docente avalie todas as discussões com tranquilidade, tendo o conhecimento da quantidade e da qualidade das interações dos alunos.

Rodrigues (2013, p. 50) destaca em relação a qualidade das contribuições dos participantes:

\footnotetext{
A qualidade das contribuições é muito importante e essencial para que o professor perceba e avalie o nível de conhecimento dos seus participantes, verificando assim, o que foi aprendido. Não adianta o aluno participar só por participar, ele tem que participar de forma crítica, atuante e colaborativa. Precisa ser ativo e atuante, uma vez que ele é responsável pela aquisição da sua própria aprendizagem. Isso é necessário para que o fórum seja um instrumento adequado no processo de avaliação da aprendizagem dos participantes (RODRIGUES, 2013, p. 50).
}

Nessa perspectiva, compreendemos que, para o fórum ser um instrumento apropriado no processo avaliativo, é fundamental que os professores-tutores avaliem todas as postagens e enviem os feedbacks necessários aos seus alunos de forma interativa, para incentivar a construção do conhecimento de forma colaborativa. Além disto, os professores-tutores por meio do fórum precisam verificar o desempenho dos alunos, e a qualquer momento esclarecer dúvidas, rever metodologias e até mudar e acrescentar conteúdo. Esta flexibilidade no fórum educativo permite que o processo de aprendizagem possa ocorrer de maneira efetiva. 
Ressalta Silva (2006), que para avaliar a participação de um aluno em um fórum educativo, é apropriado considerar a qualidade de suas mensagens e/ou discussões como também sua assiduidade. Além disso, a clareza nos critérios e o reconhecimento dos valores humanos são elementos que precisariam estar, eternamente, presentes na prática avaliativa dos professores (BOTH, 2012).

\section{PERCURSO METODOLÓGICO}

A pesquisa foi realizada no Instituto Federal de Educação, Ciência e Tecnologia do Piauí - IFPI - Campus Teresina Zona Sul e no polo Dirceu, tendo como sujeitos 57 (cinquenta e sete) alunos do curso técnico Serviços Jurídicos, na modalidade a distância e 04 (quatro) professores-tutores a distância.

Dos 57 (cinquenta e sete) alunos que responderam o questionário, 23 (vinte e três) são do sexo masculino e 34 (trinta e quatro) do feminino, sendo que a faixa etária gira em torno de 18 a 48 anos, na qual a maioria está entre 21 a 30 anos. Estes alunos possuem uma qualificação acima da exigida para iniciar o curso, ensino médio 20 (vinte), 16 (dezesseis) estão fazendo o ensino superior, 12 (doze) concluíram a graduação e 09 (nove) pós-graduação especialização. A maior parte desses alunos, 35 (trinta e cinco), está tendo a primeira experiência em curso na modalidade a distância.

Utilizamos a pesquisa de campo com abordagem qualitativa, que aproxima o pesquisador com o objeto investigado e os instrumentos de coleta de dados empregados foram: entrevista semiestrutura com os professores-tutores e observação no Ambiente Virtual de Aprendizagem - AVA do curso.

Para Oliveira a pesquisa qualitativa possibilita:

[...] processo de reflexão e análise da realidade através da utilização de métodos e técnicas para compreensão detalhada do objeto de estudo em seu contexto histórico e/ou segundo sua estruturação. Esse processo implica em estudos segundo a literatura pertinente ao tema, observações, aplicações de questionários, entrevistas e análise de dados, que deve ser apresentada de forma descritiva (OLIVEIRA, 2008, p. 37).

Em decorrência desses procedimentos adotados, a pesquisa qualitativa vem sendo utilizada em investigações, onde o objeto de estudo está relacionado às instituições educacionais. Além disso, favorece a aproximação do pesquisador com o objeto pesquisado, permitindo a verticalização do estudo que poderá ser proposto.

Vale ressaltar que, durante a análise dos dados, para resguardar a identidade dos professores-tutores, utilizamos os seguintes codinomes: percepção, emoção, empatia e afetivo.

\section{ANÁLISE E DISCUSSÃO DOS RESULTADOS}

No âmbito da EaD há a presença o professor-tutor no processo de avaliação de aprendizagem, que pode ocorrer na forma presencial, com a correção das atividades realizadas no polo, como também virtual, por meio das ferramentas comunicacionais presentes na plataforma de aprendizagem. Assim, daremos destaque a esta avaliação online, pois este estudo teve como foco analisar as 
práticas avaliativas do professor-tutor a distância, que avalia a aprendizagem por meio das discussões na ferramenta interativa fórum, objeto dessa pesquisa.

É importante destacar que, segundo a Resolução no 021/2015 do Conselho Superior, do Instituto Federal de Educação, Ciência e Tecnologia do Piauí, que estabelece normas e procedimentos didático-metodológicos para os Cursos Técnicos de nível médio na modalidade a distância, no âmbito do IFPI, estabelece no inciso XIV, do artigo 38, como uma das atribuições do professor-tutor: "XIV. Fazer a avaliação dos fóruns e lançamento das notas na plataforma AVA".

Diante dessa informação, analisamos o Projeto Pedagógico do Curso - PPC Serviço Jurídico e percebemos que o fórum é o principal instrumento utilizado para avaliar os alunos no Ambiente Virtual de Aprendizagem - AVA, conforme tabela 1, abaixo.

Tabela 1 - Instrumentos avaliativos com percentual de notas

$\begin{array}{cc}\text { Atividades } & \text { Desempenho } \\ \text { Avaliação presencial } & 40 \% \\ \text { Participação nos fóruns } & 40 \% \\ \text { Realização e entrega das atividades online } & 20 \% \\ \text { e presenciais } & 100 \%\end{array}$

Fonte: Projeto Pedagógico do Curso Serviço Jurídico, 2014 - adaptado pela autora.

A informação que participação nos fóruns correspondem a $40 \%$ da nota numérica, obedecendo a escala 0 (zero) a 10 (dez) pontos, sendo a média 7,0 (sete) para aprovação do aluno, comprova a participação dos alunos nos fóruns ser fundamental para que eles obtenham aprovação no curso. Este dado evidência a importância deste estudo, o de identificar as mediações pedagógicas e investigar as sensibilidades dos professores-tutores no processo de avaliação dos alunos no fórum. Assim sendo, analisamos por meio do conceito de Sensibilidade de Sandra Pesavento (2001, p. 225), "como uma forma de reconhecimento e tradução da realidade que brota não do racional ou das construções mentais mais elaboradas, mas dos sentidos, que vêm do íntimo de cada indivíduo", as práticas avaliativas no fórum, exposta no próximo tópico.

\section{SENSIBILIDADES EDUCATIVAS DO PROFESSOR-TUTOR NA AVALIAÇÃO DO FÓRUM E MEDIAÇÕES PEDAGÓGICAS}

Neste item apresentaremos a análise das sensibilidades presentes nas práticas avaliativas dos professores-tutores e suas mediações no fórum de discussão. Todavia, para tratarmos da sensibilidade, precisamos, inicialmente, entendermos qual o sentido que estamos atribuindo a esse termo tão amplo, para não nos levarmos a equívocos.

O termo sensibilidade não é recente e teve vários significados no decorrer dos séculos. Tendo aparecido por volta do século XIV na linguagem ocidental. Seu sentido foi se alterando segundo as representações coletivas e imaginárias de cada sociedade, período e lugar (SANTOS, 2005). 
Começamos salientando o que alguns autores falam a respeito dessa temática: sensibilidade. Para os autores Hermann (2005) e Galeffi (2007) o termo sensibilidade tem relação com a palavra estética, que é derivada do termo grego aisthesis, na qual significa sensibilidade, sensação, percepção sensível. Corroborando Rosenfield (apud FISCHER, 2015, p. 11) afirma que:

A palavra "estética" vem do grego aísthesis, que significa sensação, sentimento. Diferentemente da poética, que já parte de gêneros artísticos constituídos, a estética analisa o complexo das sensações e dos sentimentos, investiga sua integração nas atividades físicas e mentais do homem, debruçando-se sobre suas produções (artísticas ou não) da sensibilidade, com o fim de determinar duas relações com o conhecimento, a razão e a ética (ROSENFIELD, 2006, p.7).

Dessa maneira, para esses autores, no aspecto semântico, as palavras: estética e sensibilidade são sinônimos. Enquanto para Pesavento, o termo sensibilidade é bem abrangente quando destaca que:

\begin{abstract}
Sensibilidade se exprime em atos, em ritos, em palavras e imagens, em objetos da vida material, em materialidades do espaço construído. Falam, por sua vez, do real e do não real, do sabido e do desconhecido, do intuído ou pressentido ou do inventado. Sensibilidades remetem ao mundo do imaginário, da cultura e seu conjunto de significações construído sobre o mundo. Mesmo que tais representações sensíveis se refiram a algo que não tenha existência real ou comprovada, o que se coloca na pauta de análise é a realidade do sentimento, a experiência sensível de viver e enfrentar aquela representação (PESAVENTO, 2003, p. 58).
\end{abstract}

Esta conceituação é importante porque é exatamente a realidade sensível nas vozes, palavras e ações do professor-tutor em suas práticas educativas, que se percebem as manifestações que não vêm no conhecimento cientifico, mas dos sentidos, emoções e percepções que cada indivíduo foi construindo durante sua trajetória de vida.

Nesta dimensão sensível, regida por sentimentos e emoções, que não se conduzem por leis, regras ou razões, mas que se materializam e exteriorizam nas ações e falas dos professores-tutores é que nos animamos por esse desafio de analisar as sensibilidades nas práticas avaliativas no fórum.

É oportuno ressaltarmos Pesavento (2005, p. 42), “O mundo do sensível é difícil de ser quantificado". Deste modo, fizemos a análise a partir da abordagem qualitativa, utilizando a técnica de interpretação de dados: análise de conteúdo, com as categorias: mediações pedagógicas dos professores-tutores nos fóruns avaliativos e percepção sensível à dificuldade dos alunos.

Iniciamos a investigação das sensibilidades nas práticas avaliativas, primeiramente nos discursos presentes nas mediações dos professores-tutores nos fóruns avaliativos. Realizamos a análise dessas mediações com a contribuição teórica de Vectore (2006) apud Tijiboy et al. (2009), que ressalta o comportamento do mediador partindo de uma Escala de Comportamentos Mediacionais, sendo eles: Focalização (direcionar o aluno para a atividade, por meio de explicações, exemplos e questionamentos), Afetividade (incentivar a participação do aluno, ter empatia com a realidade de cada aluno, criar harmonia no ambiente de aprendizagem online) e Expansão (reforçar o conteúdo dando exemplos concretos a partir de um posicionamento do aluno). Além destes, também entendemos 
adequado para essa análise usarmos a categoria de mediação criada no estudo de Tijiboy et al. (2009) nomeado: Reflexão, onde o professor-tutor provoca o raciocínio crítico do aprendiz por meio de questionamentos para solucionar uma problemática.

De tal modo, elaboramos os seguintes gráficos $01,02,03$ e 04 , os quais destacam tipos de mediações pedagógicas dos professores-tutores nos fóruns avaliativos de seis disciplinas do curso: Serviços Jurídicos.

Observemos os gráficos:

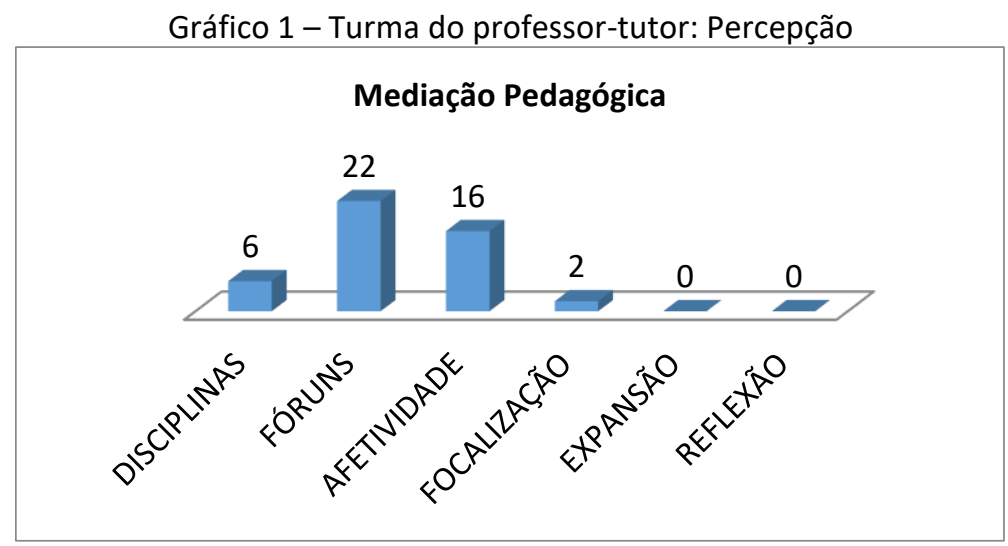

Fonte: Pesquisa da autora (2016).

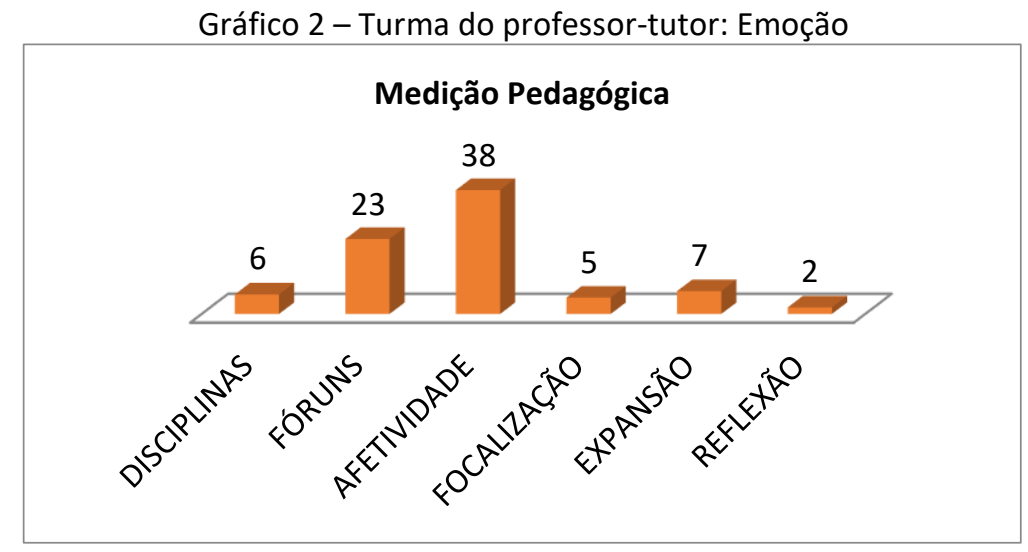

Fonte: Pesquisa da autora (2016).

Gráfico 3-Turma do professor-tutor: Empatia

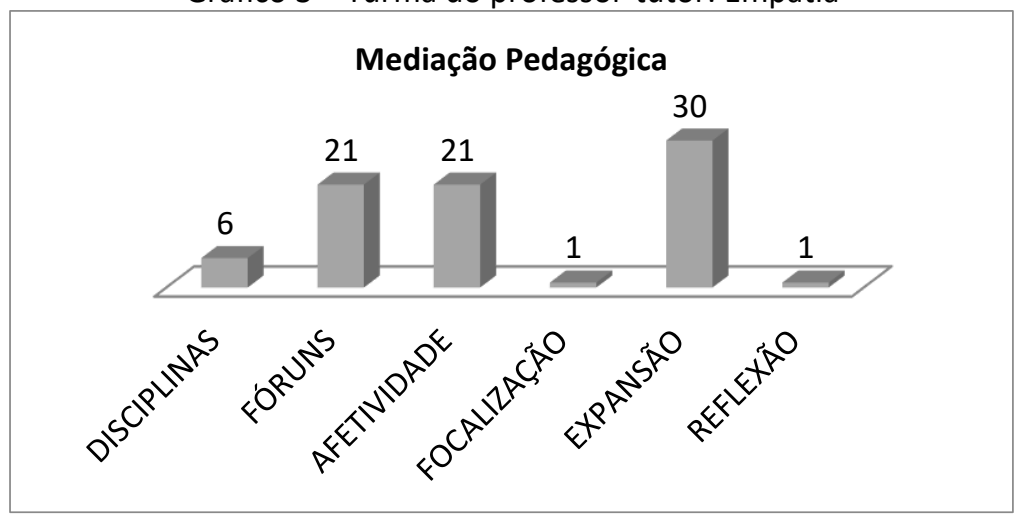

Fonte: Pesquisa da autora (2016). 


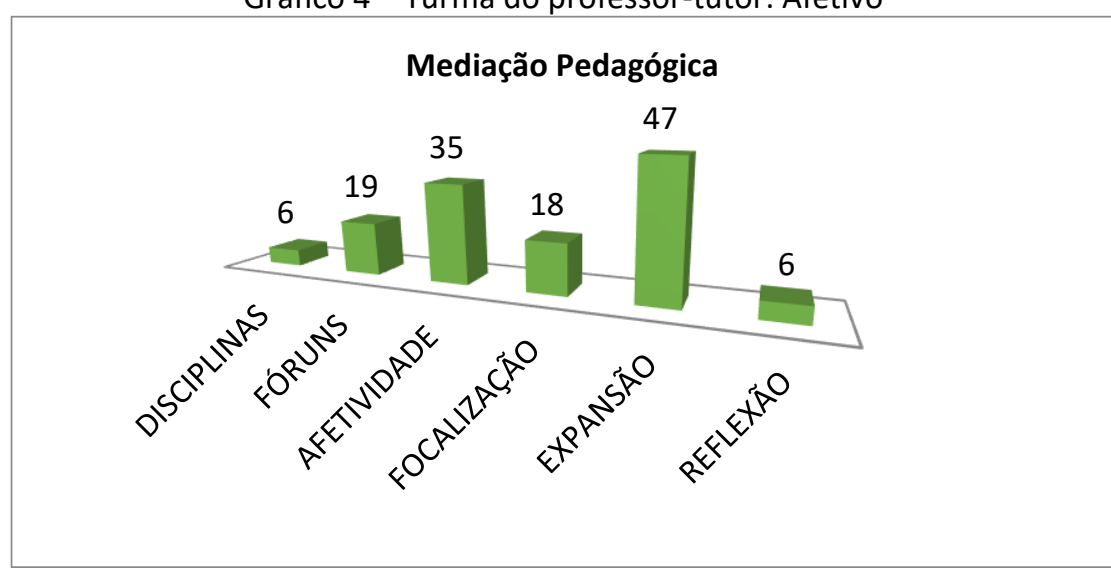

Fonte: Pesquisa da autora (2016).

Percebemos pelos gráficos acima que dois professores-tutores (Percepção e Emoção) realizaram uma quantidade maior de mediações denominada "afetividade", bem como estimulavam a participações dos alunos nos fóruns e criavam um clima de empatia e harmonia nessa ferramenta, como verificado no momento que observamos os diálogos na plataforma de aprendizagem.

Acerca da atuação do tutor para ascensão da afetividade, afirma Oliveira:

A atuação do tutor para a promoção da afetividade deve acontecer no sentido do acolhimento, do acompanhamento qualitativo do aluno, procurando conhecê-lo, saber das suas dificuldades, valorizá-lo. É imponte também considerar o perfil do aluno, que precisa estar disponível e motivado à participação. O próprio conteúdo do curso pode ser um elemento de motivação, pois vem atender a uma necessidade de formação, sentida pelo professor, para a utilização efetiva das TIC disponíveis na escola (OLIVEIRA, 2009, p.14).

Compreendemos que, o professor-tutor para promover a afetividade precisa ser sensível em suas práticas pedagógicas, pois ao conhecer a realidade do aluno, suas dificuldades e qualidades possibilitará uma avaliação justa e formativa.

Nesse contexto, afirma Medeiros:

[...] sobre a atuação do tutor em um fórum, para além do registro escrito, da postagem de uma mensagem, mas que vai desde a consideração ao que é escrito até a reorientação da discussão e à proposição de aprofundamentos a partir do que está sendo posto. Considerar e valorizar as participações dos alunos significa, em sua mensagem, o tutor se referir claramente às mensagens anteriores, seja para concordar, discordar ou propor questionamentos. $O$ aluno necessita perceber que suas contribuições estão sendo lidas e consideradas (MEDEIROS, 2013, p. 275).

Este autor ressalta que as ações pedagógicas do professor-tutor no fórum avaliativo vão além de um registro de notas. O educador deve apreciar as discussões dos alunos, acompanhar as interações e mediar os conhecimentos. Além disto, o aluno precisa sentir que sua aprendizagem está sendo acompanhada.

Assim, entendemos que um dos aspectos fundamentais para compreender melhor as sensibilidades nas práticas avaliativas dos professores-tutores é ouvindo suas vozes, e esta será a próxima análise apresentada. 
Para tanto, com o objetivo de compreendermos as sensibilidades dos professores-tutores acerca da falta de participação dos discentes nos fóruns, fizemos a seguinte pergunta: qual a forma de sensibilizar os alunos a participarem dos fóruns?

Os professores-tutores Emoção e Afetivo demonstraram em suas falas que relembram aos alunos que o fórum é um instrumento avaliativo, necessário para aprovação: "eu vou já corrigir, colocar a nota, para que eles tenham esse compromisso em terminar e fazer, porque eles sabem da importância que eu já disse e digo sempre para eles dos fóruns, até em questão na avaliação, da nota final deles" (EMOÇÃO); "usamos sempre como meio avaliativo, pois eles precisam fazer para obter nota" (AFETIVO). Compreendemos que, motivando dessa maneira, descaracteriza a avaliação formativa, contínua; a qual faz parte do processo de aprendizagem, desencoraja a interação ativa de muitos alunos, pois irão visualizar a participação nos fóruns, como mero cumprimento da disciplina.

Sob essa ótica, corrobora Duarte:

\begin{abstract}
Ao invés de o professor considerar as participações dos alunos apenas sob a ótica quantitativa, a maioria dos sujeitos levanta necessidade de o professor deixar claro o que espera dos alunos, desaprovando respostas vazias, valorizando as postagens pertinentes e evidenciando a importância da qualidade e não quantidade das respostas, tentando criar uma cultura de participação na qual todos efetivamente participem independente da atividade valer nota ou não (DUARTE, 2010, p. 30).
\end{abstract}

De tal modo, entendemos a necessidade de planejamento, sensibilidade e afeição dos professores-tutores na utilização do fórum como instrumento pedagógico.

O Afetivo também destacou que, motiva os discentes questionando-os a respeito dos assuntos discutidos nos fóruns, "o outro é a motivação devemos sempre os induzir a questionamentos que possam desenvolver o pensamento crítico para que eles não tenham respostas prontas e assim possam fazer pesquisas e divulgar o que pesquisaram". Desta maneira, motivar a participação dos alunos nos fóruns é uma boa estratégia de mediação, como afirma Oliveira (2010, p. 51): “Motivar a participação, problematizando, levando questões desafiadoras e esclarecendo as dúvidas, discutindo opinião faz parte de uma boa mediação no ambiente online".

Outro educador que utiliza esse mesmo método é a Percepção, que, além disto, também solicita a contribuição do professor-tutor presencial, o qual está mais próximo, fisicamente, dos alunos, a lembrá-los da importância da participação deles no fórum avaliativo. Tal fato evidencia-se nesse trecho da entrevista:

[...] sempre tento questionar de alguma forma para motivar um pouco também né, porque eles são muito desmotivados, eu acho que no início eles eram mais participativos ai eu fico muito com o X, que é o tutor presencial, eu digo sempre para ele: me ajuda! Vamos tentar resolver isso, para os alunos responderem melhor, terem mais empenho, mais vontade de participação, mas é muito difícil, muito... para responder o fórum, debater e discutir, eles ainda não estão tendo essa prática (PERCEPÇÃO). os alunos reforçando a importância da educação para a vida, bem como 
valorizando e relembrando-os sobre o fato deles terem sido aprovados em um processo seletivo; mexendo, assim, com o eco dos alunos. Isto foi demonstrado neste recorde da entrevista: "maneira de sensibilizá-los e dizer que são poucos aqueles que ainda têm acesso a esse tipo de educação. Porque eles passaram por um processo seletivo, foram aprovados, certo!"

Visualizamos marcas de sensibilidades na fala desse educador, que valorizou e deu importância à formação dos alunos, além estimular a sensibilidade desses aprendizes por meio de palavras incentivadoras, compartilhando, assim a sensibilidade que "são uma forma do ser no mundo e de estar no mundo, indo da percepção individual à sensibilidade partilhada" (PESAVENTO, 2005, p. 5).

Mais um fato relevante nas falas dos professores-tutores Emoção e Empatia, é que eles utilizam outras ferramentas tecnologias: whatsapp e e-mail para interagirem com os aprendizes. Como demonstram esses trechos da entrevista: "mas a gente tenta, envia e-mail, tenta conversar com os alunos, eu tenho com os alunos através de whatsapp, que informo toda e qualquer dúvida que eles têm, eles entram em contato comigo" (EMPATIA); "com o mecanismo de whatsapp, de e-mail e internet a nossa disposição, nós criamos grupos com os alunos que realmente participam do curso e frequentemente a gente vai cobrando, eu vou dizendo a data que eu vou fechar os fóruns" (EMOÇÃO).

Diante desse cenário, argumenta Formiga:

\begin{abstract}
Trabalhar com EAD requer profissionais e atores sensíveis e dispostos à inovação porque atuam em um setor de transitoriedade no qual a única certeza é a permanente mudança, cujas as influências chegam pelo diferentes idiomas dos países que produzem conhecimento exponencial para a área (...) não há espaço para conservadores ou acomodados, exigem-se atividades ousadas e celeridades nas decisões, que envolvem riscos nas opções com as quais se defronta (...) não há espaço para dogmas ou verdades absolutas (FORMIGA, 2009, p. 39).
\end{abstract}

Sob essa ótica, exercer a docência na EaD requer ser sensível as mudanças que ocorrer na sociedade do conhecimento, onde a inovação nas práticas pedagógicas é essencial para a efetivação das práticas educacionais.

\title{
ALGUMAS CONSIDERAÇÕES
}

Neste momento, relembramos os discursos, reflexões e olhares construídos a partir do referencial teórico, observações na plataforma de aprendizagem e depoimentos das entrevistas com os professores-tutores. Assim, as técnicas de coleta de dados possibilitaram atender os objetivos dessa pesquisa: identificar as mediações pedagógicas e analisar as sensibilidades dos professores-tutores durante a prática avaliativa no fórum do AVA - Moodle.

Nessa ótica da sensibilidade nas práticas avaliativas, onde a relação educador/educando se transforma sensivelmente na EaD, uma vez que o educador se transforma, também, em aprendiz (NEDER, 2005), compreendemos que o professor-tutor a distância precisa desenvolver seu conhecimento sensível, agindo de maneira a reconhecer e traduzir a realidade que não nasce do racional, mas das sensibilidades oriundas do íntimo de cada ser. 
Dessa maneira, observamos que a prática avaliativa dos professores-tutores a distância é fundamental para a permanência dos aprendizes no curso, porque por meio de suas mediações pedagógicas, esse educador pode desenvolver e acompanhar o conhecimento dos alunos, bem como fortalecer laços afetivos e harmoniosos no ambiente online.

Notamos que nas considerações tecidas na trajetória deste estudo, o fórum pode potencializar estratégias de avaliação, porque possibilita desenvolver discursos, autonomia e aprendizagem em rede, elementos essenciais da interatividade do AVA.

Em relação as práticas pedagógicas no fórum, verificamos que as mediações dos professores-tutores estavam focadas mais nas explicações sobre o assunto e motivação com palavras de incentivos, as quais são fundamentais para fortalecer a interação e criar um clima afetivo entre os participantes de um curso no ambiente online. No entanto, não visualizamos os professores-tutores realizando, significativamente nos fóruns, reflexões, discussões e problemáticas suficientes para instigar as participações ativas dos alunos.

Consideramos, por outro lado, que a EAD progrediu bastante com a utilização dos AVA, porém precisa avançar também nas práticas de mediação pedagógica do professor-tutor a distância para concretizar o processo de ensino e aprendizagem nesses ambientes educacionais.

Constatamos ainda em alguns posicionamentos específicos na entrevista e durante as análises das práticas avaliativas dos professores-tutores na plataforma de aprendizagem, marcas de sensibilidades, pois estes educadores durante o ato de avaliar os fóruns, tiveram empatia a situações particulares dos alunos, respeitando sua subjetividade, valorizando suas opiniões, bem como utilizando o bom senso nesse processo.

Portanto, acreditamos que determinando com nitidez os critérios avaliativos e sendo sensível às características e particularidades de cada indivíduo, o processo avaliativo poderá ser justo e fazer parte, realmente, do processo educativo. 


\title{
EDUCATIONAL SENSITIVITY IN THE LEARNING EVALUATION PROCESS IN THE DISTANCE EDUCATION FORUM
}

\begin{abstract}
Advances in Information and Communication Technologies (ICT) are enabling the growth and improvement of distance learning. However, it is essential to make reflections and discussions about some pedagogical instruments used in Distance Education - DE. Thus, this article proposes to demonstrate the result of a research that aimed to: identify the pedagogical mediations and analyze the sensitivity of online tutors of the Legal Services technical course, at the Piauí Federal Institute of Education, Science and Technology, during the evaluation practice in the Virtual Learning Environment forum - Moodle. Methodologically, we used qualitative approaches and, as data collection instruments, nonparticipatory observation in the learning platform, as well as semi-structured interviews with the online tutors. The results indicate marks of sensitivity in the online tutors' evaluation practices, because during the evaluation of the forums they demonstrated empathy with students' particular situations, respecting their subjectivity, valuing their opinions, in addition to using common sense in the evaluation process.
\end{abstract}

KEYWORDS: Distance education. Role of the online tutor. Evaluation of learning. Pedagogical mediations. Educational sensitivity. 


\section{REFERÊNCIAS}

ALONSO, Kátia Morosov. A avaliação na educação à distância: algumas notas para a reflexão. In: PRETI, Oreste (org.). Educação a distância: sobre discursos e práticas. Brasília: Liber Livro Editora, 2005.

ALVES, R. M.; ERRICO, L.; MESQUITA, R.C. Um modelo informacional para avaliações de alunos no ensino a distância via Web. In: Simpósio Brasileiro de Informática na Educação - SBIE, 13., 2002, São Leopoldo. Anais... São Leopoldo: UNISINOS, 2002. p. 464-473.

AMARILLA FILHO, Porfírio. Educação a distância: uma abordagem metodológica e didática a partir dos ambientes virtuais. Educação em Revista, v. 27, n. 2, p. 4172, 2011.

BARROS, D. M. V. et al. Educação à distância: desafios atuais. Bauru: UNESP/FC, 2008. v.1.

BASSANI, Patrícia Scheren; BEHAR, Alejandra Patrícia. Avaliação da aprendizagem em ambientes virtuais. In: BEHAR, Patricia Alejandra (org.). Modelos pedagógicos em educação à distância. Porto Alegre: Artmed, 2009, cap. 4, p. 93-113.

BOTH, Ivo José. Avaliação: "voz da consciência" da aprendizagem. Curitiba: InterSaberes, 2012.

BRASIL. Ministério da Educação. Referenciais de qualidade para a educação superior. v. 1. 2007. Disponível em: $<$ http://portal.mec.gov.br/seed/arquivos/pdf /referenciaisead.pdf>. Acesso em: 25 maio 2015.

BRASIL. Congresso Nacional. Lei no 9394/96. Estabelece a Lei de Diretrizes e Bases da Educação Nacional. 20 de dezembro de 1996.

BRUNO, Adriana; MORAES, Maria. O Enfoque da Complexidade e dos Afetos afetivo-emocionais na Avaliação da Aprendizagem em Ambientes da Aprendizagem em Educação online. São Paulo: Loyola, 2006.

CARLINI, A. L.; TARCIA, R. M. L. Contribuições didáticas para o uso das tecnologias de educação a distância no ensino presencial. IN. CARLINI, A. L.; TARCIA, R. M. L. $20 \%$ a distância e agora?: orientações práticas para o uso da tecnologia de educação a distância no ensino presencial. São Paulo: Pearson Education do Brasil, 2010. 
CORTELAZZO, Iolanda Bueno de Camargo. Prática pedagógica, aprendizagem e avaliação em educação a distância. Curitiba: InterSaberes, 2013.

DUBEUX, L. S. et al. Formação de avaliadores na modalidade educação à distância: necessidade transformada em realidade. Revista Brasileira de Saúde Materno Infantil, Recife, 2008. Disponível em: <http://www.scielo.br >. Acesso em: 23 jan. 2016.

FARIA, Adriano Antônio e LOPES, Luís Fernando. Práticas pedagógicas em EaD. Curitiba: InterSaberes, 2014.

FISCHER, Deivis Alexandre. Educação e sensibilidade: tensões e desafios. Dissertação (Mestrado em Educação). Faculdade de Educação, PUCRS. Porto Alegre, 2015. $87 \mathrm{f}$.

GALEFFI, Dante Augusto. Educação estética como atitude sensível interdisciplinar: aprender a ser o que se é propriamente. In.: Em Aberto, Brasília, v. 21, n. 77, p. 97-111, jun. 2007. Disponível em http://emaberto.inep.gov.br/index.php/emaberto/article/viewFile/1175/1074. Acesso em 08 fev. de 2016.

HERMANN, Nadja. Ética e educação: outra sensibilidade. Belo Horizonte/São Paulo: Autêntica, 2014.

Ética e estética: a relação quase esquecida. Porto Alegre: EDIPUCRS, 2005.

INSTITUTO FEDERAL DE EDUCAÇÃO CIÊNCIA E TECNOLOGIA DO PIAUÍ. Resolução no 021/2015 do Conselho Superior. Teresina-PI.

INSTITUTO FEDERAL DE EDUCAÇÃO CIÊNCIA E TECNOLOGIA DO PIAUÍ. Projeto Pedagógico do Curso Serviços Jurídicos. Teresina-PI, 2014.

LÉVY, Pierre. Cibercultura. São Paulo: Editora 34, 1999.

MATTAR, João; MAIA, Carmem. ABC DA EAD - Educação a Distância hoje. 1은 edição. São Paulo:Person Prentice Hall, 2007.

MATTAR, João. Tutoria e interação em educação a distância. São Paulo: Cengage Learning, 2012. 
MEDEIROS, Zulmira. A relação pedagógica na Educação presencial e na educação a distância. distanciamentos e proximidades. In: MILL, Daniel; MACIEL, Cristovão. (orgs) Educação a distância: elementos para pensar o ensino-aprendizagem contemporânea. Cuiabá: EdUFMT, 2013.

MOORE, Michael \& KEARSLEY, Greg. Educação a Distância: uma visão integrada. Tradução Roberto Galman. São Paulo: Cengage Learning, 2011.

MORAN, José Manuel, MASSETTO, M. T.; BEHRENS, M. A. Novas Tecnologias e mediação pedagógica. Campinas: Papirus, 2000.

MORAN, José Manuel. Os modelos educacionais na aprendizagem on-line. Site pessoal do autor. São Paulo, artigo atualizado em 2007. Disponível em: < http://www.eca.usp.br/prof/moran/site/textos/educacao online/modelos.pdf $>$. Acesso em: 27 abr. 2016.

MOULIN, N.; PEREIRA, V.; TRARBACH, M. A. Formação do tutor para as funções de acompanhamento e avaliação da aprendizagem à distância. Disponível em: < http://www.abed.org.br/congresso2004/por/htm/018-TC-A2.htm>. Acesso em: 27 abr. 2016.

OLIVEIRA, Maria Marly de. Vygotsky: aprendizado e desenvolvimento, um processo sócio-histórico. 5. ed. São Paulo: Scipione, 2010. Coleção Pensamento e Ação na Sala de Aula.

PESAVENTO, Sandra J. Ressentimentos e Ufanismo: sensibilidade do Sul profundo. In: BRESCIANI, Stella e NAXARA, Márcia. Memória (re)sentimento. Indagações sobre uma questão sensível. Campinas: Ed. da UNICAMP, 2001.

História \& História Cultural. Belo Horizonte: Autêntica, 2003.

Sensibilidades no tempo, tempo das sensibilidades, Nuevo Mundo Mundos Nuevos [En línea], Coloquios, Puesto en línea el 04 febrero 2005. Disponível em: http://nuevomundo.revues.org/229. Acesso em: 01 mar. 2016.

PRIMO, Alex. Avaliação em Processo de educação problematizadora on line. In: SILVA, Marco; SANTOS, Edméa (org). Avaliação da Aprendizagem em Educação online. São Paulo: Edições Loyola, 2006.

SILVA, Marco. Avaliação da aprendizagem em educação online. São Paulo, SP: 
SILVA, Marinilson Barbosa. O processo de construção de identidades individuais e coletiva do ser-tutor no contexto da educação a distância, hoje. Tese de doutorado - Programa de Pós-graduação em Educação, UFRGS, Porto Alegre, 2008.

SANTOS, Nádia Maria Weber. História de sensibilidades: espaços e narrativas da loucura em três tempos (Brasil, 1905/1920/1937). 2005.

RODRIGUES, Nice Vânia Machado. Avaliação da aprendizagem em educação a distância através do fórum (INTERFACE EDUCACIONAL). Interfaces Científicas Educação, Aracaju. v.01, n.03, p. 43-53, jun. 2013

ROSSATO, Maristela, RAMOS, Wilsa Maria, MACIEL, Diva Maria Albuquerque. Subjetividade e Interação nos Fóruns Online: Reflexões sobre a Permanência em Educação a Distância. Revista Reflexão e Ação, Santa Cruz do Sul, v.21, n.2, p. 399 - 429, jul./dez. 2013.

SÁ, Iranita M. A. Educação a Distância: Processo Contínuo de Inclusão Social.Fortaleza, C.E.C., 1998.

SILVA, Marco. Avaliação da aprendizagem em educação online. São Paulo, SP: Loyola, 2006.

SILVA, Marinilson Barbosa. 0 processo de construção de identidades individuais e coletiva do ser-tutor no contexto da educação a distância, hoje. Tese de doutorado - Programa de Pós-graduação em Educação, UFRGS, Porto Alegre, 2008.

SANTOS, Edméa Oliveira. Educação online. Cibercultura e pesquisa-formação na prática docente. Tese de Doutorado em Educação. Faculdade de Educação. Universidade Federal da Bahia - FACED/UFBA. Salvador, 2005.

TIJIBOY, Ana Vilma et al. Compreendendo a Mediação do Tutor a Distância. In.: CITED-UFRGS Novas Tecnologias na Educação. v.7, no. 1, Jul. 2009.

VILLARDI, Raquel e OLIVEIRA, Eloíza Gomes. Tecnologia na Educação: Uma perspectiva sócio-interacionista. Rio de Janeiro: Dúnya, 2005. 
Recebido: 20 mai. 2017

Aprovado: 17 jun. 2020

DOI: $10.3895 /$ rbect.v13n2.5923

Como citar: SOUSA, F. A.; OLIVEIRA, I. B. Sensibilidades educativas no processo de avaliação de

aprendizagem no fórum de discussão da EaD. Revista Brasileira de Ensino de Ciência e Tecnologia,

Ponta Grossa, v.13, n. 2, p.106-126, mai./ago. 2020. Disponível em:

<https://periodicos.utfpr.edu.br/rbect/article/view/5923>. Acesso em: XXX

Correspondência: Fabiana Araújo Sousa - fabianaifpi@gmail.com

Direito autoral: Este artigo está licenciado sob os termos da Licença Creative Commons-Atribuição 4.0 Internacional. 